\title{
Morphometric Assessment of Orbit in Human Skull
}

\author{
Moizuddin Jawaduddin Khwajaํㅜ, Siraj Ahmed Hasham Shaikh², Sanket Dadarao Hiware ${ }^{3}$, Syed Rehan Hafiz Daimi ${ }^{4}$, \\ Asim Mohsin Badaam5, Faiza Banu Siddiqui6, Pradeep Bokariya7, Nidhi Sharma ${ }^{8}$ \\ 1, 2, 3, 4, 5, 6 Department of Anatomy, College of Medicine, Imam Abdulrahman Bin Faisal \\ University, KSA, Saudi Arabia. ${ }^{7}$ Department of Anatomy, Mahatma Gandhi Institute of \\ Medical Sciences, Wardha, Maharashtra, India. ${ }^{8}$ Department of Anatomy, Teerthankar \\ Mahaveer Medical College, TMU, Moradabad, Uttar Pradesh, India.
}

\section{ABSTRACT}

\section{BACKGROUND}

The orbits are four-sided pyramidal cavities present in normal frontalis in skull. We wanted to evaluate the sexual dimorphic morphometry of orbit in skull bones.

\section{METHODS}

45 adult dry skulls of both genders were studied. Parameters such as orbital height, orbital breadth, orbital index (OI = height of orbit / orbital breadth $\times 100$ ), orbital rim perimeter, orbital opening area ( $22 / 7 \times \mathrm{AB}$ where $\mathrm{A}$ and $\mathrm{B}$ are the halves of orbital height and breadth respectively) were recorded.

\section{RESULTS}

Out of 45 skulls, 25 were of males and 20 were of females. The mean orbital height was found to be $35.4 \pm 3.8 \mathrm{~mm}$ and $33.4 \pm 3.4 \mathrm{~mm}$ in males and females respectively, orbital breadth was $43.7 \pm 4.3 \mathrm{~mm}$ and $42.1 \pm 4.1 \mathrm{~mm}$ in males and females. The mean value for orbital index in males was $84.2 \pm 7.1$ and in females was $81.6 \pm 8.2$, orbital rim perimeter in males was $12.6 \pm 2.5 \mathrm{~cm}$ and in females was $11.3 \pm 2.2 \mathrm{~cm}, 12.4 \pm 2.1$ $\mathrm{cm}^{2}$ and $11.1 \pm 2.0 \mathrm{~cm}^{2}$ was orbital opening area in males and females. It was found in the study that the mean bony orbital volume in males was $28.8 \pm 3.4 \mathrm{~mL}$ and in females was $25.2 \pm 3.2 \mathrm{~mL}$. A non-significant $p$ value $(p>0.05)$ was obtained. Round shaped orbit was seen in 9 males and 16 females and square shaped orbits in 14 males and 6 females. A non-significant difference was seen $(\mathrm{p}<0.05)$.

\section{CONCLUSIONS}

Authors found that average orbital parameter measurements were more in males as compared to females with significant difference.
Corresponding Author: Moizuddin Jawaduddin Khwaja, Department of Anatomy, College of Medicine, Imam Abdulrahman Bin Faisal University, KSA, Saudi Arabia. E-mail: kmoizuddin@iau.edu.sa

DOI: $10.14260 / j e m d s / 2020 / 796$

How to Cite This Article:

Khwaja MJ, Shaikh SH, Hiware SD, et al. Morphometric assessment of orbit in human skull. J Evolution Med Dent Sci 2020;9(48):3624-3627, DOI: 10.14260/jemds/2020/796

Submission 19-08-2020, Peer Review 14-10-2020, Acceptance 20-10-2020, Published 30-11-2020.

Copyright (C) 2020 Siraj Moizuddin Jawaduddin Khwaja et al. This is an open access article distributed under Creative Commons Attribution License [Attribution 4.0 International (CC BY 4.0)]

\section{KEY WORDS}

Morphometric, Orbit, Breadth 


\section{BACKGROUND}

The orbital cavity contains the visual apparatus including the eyeball, muscles, vessels, nerves, lacrimal apparatus, and fascial strata. It has been observed that various events such as neoplastic, congenital, vascular, endocrine disorders and traumatic etc. affect greatly the orbit. ${ }^{1}$ Craniofacial asymmetry can be assessed by the measuring bony orbital volume (BOV) and orbital shape. It is evident that this morphometric study is valuable in assessing injury severity and complications in preoperative strategy and helps in fruitful planning. ${ }^{2}$

Orbits are four-sided pyramidal cavities, with its base opens into the face. It has four borders, frontal bone forms the superior margin, maxilla and zygomatic forms the inferior margin, inferior margin is formed by maxillary and zygoma and lateral border is formed by zygoma and frontal bone. Orbit apex is approximated by the medial end of superior orbital fissure. It in linked with middle cranial fossa through optic canal. ${ }^{3}$ Bony orbits are made up of 7 bones i.e., frontal bone (pars orbitalis), lacrimal bone, ethmoid bone (lamina papyracea), zygomatic bone, orbital surface of the body of the maxilla), orbital process of palatine bone and greater and lesser wing of sphenoid bone. ${ }^{4}$

The orbital approaches in orbital surgeries may be extraorbital surgical approaches for orbital tumours or transorbital surgical approaches. It is evident that the cranioorbitozygomatic approach helps in accessing numerous pathologies involving the skull base and the unreached areas under the brain. Inferior orbital fissure is a vital and important anatomical area in such surgeries in which some of the skull base osteotomies expand. There is requirement of recognizing inferior orbital fissure. Various surgical interventions such as maxillectomy is complicated by injuries to the orbital contents, ethmoidal arteries, lacrimal apparatus as well as optic nerve. Hence it becomes necessary to have thorough and extensive knowledge of local anatomy. Transcranial approach can be used for removal of the cranioorbital tumours completely. ${ }^{5}$ The trans-orbital surgical approach can reach the lateral compartment of the orbit through tinclude: the lateral approach; the superior approach makes entry into the superior orbit and is the only route which can explore all parts of the optic nerve even the optic canal. The superolateral approach has advantages over the two preceding routes, as it gives access to the superior and lateral parts of the orbit.

Huanmanop et $\mathrm{al}^{6}$ showed the length of the orbit on the right side in males was $4.52 \mathrm{~mm}$ and left side was $4.54 \mathrm{~mm}$. In females on the right side was $4.38 \mathrm{~mm}$ and left side was 4.43 . They found that the roof of the orbit is very thin, but reinforced laterally by greater wing of sphenoid and anteriorly by supra orbital margin.

Shimizu et $\mathrm{al}^{7}$ found that in the lateral orbital wall, the lateral surgical approach involves several procedures, including exploration for fractures, decompression, excision of the lacrimal gland, and orbitozygomtic craniotomy. The mean measured distances from FZ to SOF, FZ to IOF, and FZ to OC were $39.94 \mathrm{~mm}, 29.08 \mathrm{~mm}, 44.25 \mathrm{~mm}$, respectively, in males, and $39.12 \mathrm{~mm}, 27.32 \mathrm{~mm}, 43.58 \mathrm{~mm}$, respectively, in females. The values of FZ-SOF distance are greater than those measured in Indian (35 mm), in U.S. (36.59 mm), Korean (34.3 mm), and Thai individuals $(34.3 \mathrm{~mm})$. Also, the distance from FZ-IOF is greater than that measured in Indian (25 mm), Korean (24.8 $\mathrm{mm})$ and Thai individuals $(24 \mathrm{~mm})$ but less than that of U.S.
(40.92 mm). The present study aimed to measure the bony orbit in detail in adult dry adult skulls and also to study side and sex differences.

\section{METHODS}

This prospective observation study consisted of 45 adult dry skulls of both genders and study was commenced in Anatomy department. Institutional ethical committee approved the study. A simple random method was used for the skull selection. The ages at death of the individuals were estimated using dental eruption, tooth wear and cranial suture closure. Sex was determined using standard criteria in forensic medicine, including robusticity of the supraorbital, occipital and mastoid regions, and characteristics of the mid sagittal curve of the neurocranium. The skulls with damage, malformations or any other pathologies were excluded.

Parameters such as orbital height, orbital breadth, orbital index $(\mathrm{OI})=$ height of orbit $/$ orbital breadth $\times 100$, orbital rim perimeter, orbital opening area $=22 / 7 \times \mathrm{AB}$ where $\mathrm{A}$ and $\mathrm{B}$ are the halves of orbital height and breadth respectively were recorded. 8

The materials required for the study were thread, metallic scale and vernier callipers. Two measurements were made for each parameter to get an average value. The methods employed were:

1. In the case of shape both sides' orbits were visualized assessed to determine whether square or round.

2. The Perimeter $(\mathrm{Pm})$ of the orbit was measured by pressing a loop of thread along the outer margin of orbit. The thread was then measured on a metallic scale and the readings were noted.

3. The Height of the orbit (Ht) was calculated as the distance between upper and lower orbital margins.

4. Breadth $(\mathrm{Br})$ of the orbit was the medio-lateral distance of orbit measured with the help of vernier calipers.

5. Orbital Index was calculated as- Orbital Index = Orbital height divided by Orbital breadth $\times 100$.

Based on measurement obtained with above parameters, orbits were classified into:

1. Megaseme (Large): The orbital index is 89 or over.

2. Messeme (Intermediate): Orbital index between 83 to 89 .

3. Microseme (Small): Orbital index 83 or less.

4. Length of the lateral wall of the orbit was measured from the midpoint of the lateral margin of the orbit to the apex of the orbit using a thick strip of paper. The length of the paper was then measured using metallic scale and Vernier callipers.

5. Length of the medial wall of the orbit was measured from the midpoint of medial wall of the orbit to the apex of the orbit.

6. Roof length of the orbit was measured from the midpoint of the upper margin of the orbit to the apex of the orbit.

7. Floor and Length of the orbit was measured from the midpoint of the lower margin of the orbit to the apex of the orbit.

8. Intra orbital distance was calculated between the mid points of medial margins of two orbits.

9. Extra orbital distance was calculated between the mid points of lateral margins of two orbits. 


\section{Statistical Analysis}

Data thus obtained was tabulated for correct inference. It was expressed as mean \pm SD. SPSS version 20.0 software was used for this study. Chi-square test was used. A value of 0.05 was designated as significant.

\section{RESULTS}

\begin{tabular}{|ccc|}
\hline Gender & Male & Female \\
\hline Number & $25(55.5 \%)$ & $20(45.5 \%)$ \\
& Total $=45$ & \\
\hline \multicolumn{2}{|c|}{ Table 1. Gender Wise Skull Distributions } \\
\hline
\end{tabular}

The data measured regarding general parameters for the right and left orbits in male skulls are shown in Table 1 and 2. Table 1 shows that out of 45 skulls, 25 were of males and 20 were of females. On comparing the data statistically among male and female population, the authors observed no statistical difference in between $(p>0.05)$.

\begin{tabular}{|cccc|}
\hline Mean Parameters & Male & Female & P Value \\
\hline Orbital Height $(\mathrm{mm})$ & $35.4 \pm 3.8$ & $33.4 \pm 3.4$ & 0.05 \\
Orbital Breadth $(\mathrm{mm})$ & $43.7 \pm 4.3$ & $42.1 \pm 4.1$ & 0.02 \\
\hline Orbital Index & $84.2 \pm 7.1$ & $81.6 \pm 8.2$ & 0.01 \\
Orbital Rim Perimeter $(\mathrm{cm})$ & $12.6 \pm 2.5$ & $11.3 \pm 2.2$ & 0.02 \\
Orbital Opening Area (cm $\left.{ }^{2}\right)$ & $12.4 \pm 2.1$ & $11.1 \pm 2.0$ & 0.01 \\
Bony Orbital Volume $(\mathrm{mL})$ & $28.8 \pm 3.4$ & $25.2 \pm 3.2$ & 0.02 \\
\hline \multicolumn{3}{|c|}{ Table 2. Assessment of Parameters of Orbits } \\
\hline \multicolumn{4}{|c}{} \\
\hline
\end{tabular}

Table 2 shows that mean orbital height found to be $35.4 \pm$ $3.8 \mathrm{~mm}$ and $33.4 \pm 3.4 \mathrm{~mm}$ in males and females respectively, orbital breadth was $43.7 \pm 4.3 \mathrm{~mm}$ and $42.1 \pm 4.1 \mathrm{~mm}$ in males and females. The mean value for orbital index in males was $84.2 \pm 7.1$ and in females was $81.6 \pm 8.2$, orbital rim perimeter in males was $12.6 \pm 2.5 \mathrm{~cm}$ and in females was $11.3 \pm 2.2 \mathrm{~cm}$, $12.4 \pm 2.1 \mathrm{~cm}^{2}$ and $11.1 \pm 2.0 \mathrm{~cm}^{2}$ was orbital opening area in males and females. The mean bony orbital volume was $28.8 \pm$ $3.4 \mathrm{~mL}$ in males and $25.2 \pm 3.2 \mathrm{~mL}$ in females. A significant $\mathrm{P}$ value was obtained on comparing orbital height, orbital breadth, orbital index, orbital rim perimeter, Orbital opening area and bony orbital volume $(\mathrm{p}<0.05)$.

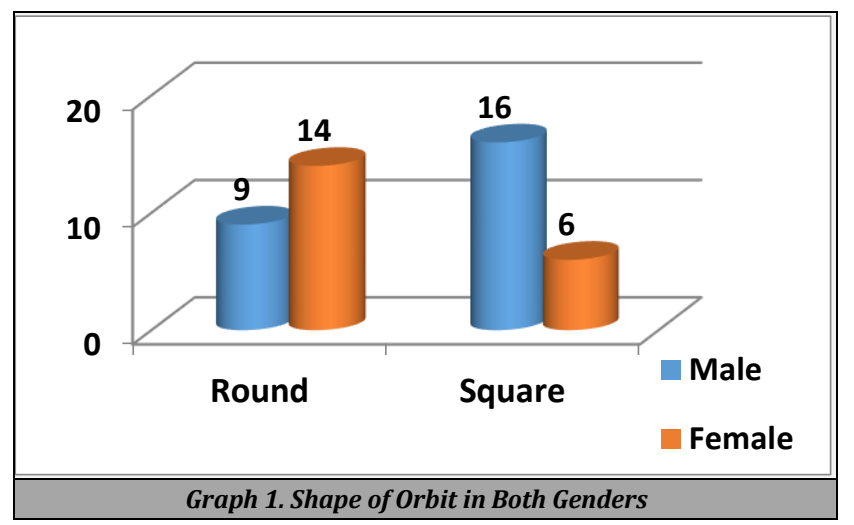

Graph 1 shows that round shaped orbit was seen in 9 males and 16 females and square shaped orbits in 14 males and 6 females. On comparing the data statistically among male and female population, the authors observed no statistical difference in between $(p>0.05)$.

\section{DISCUSSION}

The orbits are located on front part of skeletal. It contains eyes and can be comparable to both having expensive matter. As described in literature, it is a 4 sided pyramid with base located anteriorly and apex pointed posteriorly. Surgeons should be thorough with the anatomical landmarks, marking, attachment and contents of orbits in ensuring successful surgical interventions. This in turn decides selection of correct approach for surgery.

Orbital pathologies can only be evaluated and subsequently classified if there is better access as well as the knowledge of area concerned. Anthropometry is the recording of variation in measurements of the human individual. Selection of specific approach helps in treatment planning. Orbits are exposed in numerous surgical processes such as in case of enucleation of orbits, orbital and optic nerve decompression, exenteration and vascular ligation. ${ }^{8}$

Iatrogenic trauma and injury may only be inhibited if the surgeon is well versed with the anatomy of orbit especially neurovascular bundles passing through various foramina and fissures. ${ }^{9}$ The locations of various foramina in the orbit vary in different ancestral populations. ${ }^{10}$ On the basis of accurate anthropological measurements, the congenital or posttraumatic facial disfigurements can be treated.11 The recent research by various authors shows there is significant variation in morphometry of ocular and orbit among different races $^{12}$ Hence in this study we evaluated morphometric study of orbit in skull bones.

In present study, out of 45 skulls, 25 were of males and 20 were of females. Gosavi et $\mathrm{al}^{13}$ assessed ocular and orbital morphometry in 64 intact skulls i.e., 128 orbits. In this study orbital height found to be $32.31 \pm 2.52 \mathrm{~mm} .39 .46 \pm 2.57 \mathrm{~mm}$ was the mean orbital width. The value for orbital index was $81.88 \mathrm{~mm}$. The mean Bi orbital distance was $95.65 \pm 3.48 \mathrm{~mm}$ and the mean interorbital distance was $19.49 \pm 3.35 \mathrm{~mm}$. Authors provided useful information that orbital morphometry is essential to demonstrate ophthalmological, maxillary surgeries and facial reconstructive cosmetic surgeries. Detail knowledge of anatomy and its variations will help the surgeons to avoid surgical complications.

In this study, mean orbital height found to be $35.4 \pm 3.8$ $\mathrm{mm}$ and $33.4 \pm 3.4 \mathrm{~mm}$ in males and females respectively, orbital breadth was $43.7 \pm 4.3 \mathrm{~mm}$ and $42.1 \pm 4.1 \mathrm{~mm}$ in males and females. The mean value for orbital index in males was $84.2 \pm 7.1$ and in females was $81.6 \pm 8.2$, orbital rim perimeter in males was $12.6 \pm 2.5 \mathrm{~cm}$ and in females was $11.3 \pm 2.2 \mathrm{~cm}$, $12.4 \pm 2.1 \mathrm{~cm}^{2}$ and $11.1 \pm 2.0 \mathrm{~cm}^{2}$ was orbital opening area in males and females. The mean bony orbital volume was $28.8 \pm$ $3.4 \mathrm{~mL}$ in males and $25.2 \pm 3.2 \mathrm{~mL}$ in females. A significant $\mathrm{P}$ value was obtained. Fetouh et al ${ }^{14}$ conducted a study involving 52 adult skulls and the dimensions of orbits was determined. There was significant difference in mean orbital height (males - $35.57 \mathrm{~mm}$, females - $35.12 \mathrm{~mm}$ ), the mean orbital breadth (43.25 $\mathrm{mm}$ in males, $42.37 \mathrm{~mm}$ in females), the mean orbital index (82.27 - males, 82.5 - females). Similarly, there was significant difference in findings of orbital rim perimeter which was $12.60 \mathrm{~cm}$ in males and $12.28 \mathrm{~cm}$ in females. Males exhibited $12.08 \mathrm{~cm}^{2}$ mean orbital opening area in males and $11.71 \mathrm{~cm}^{2}$ in females and $28.75 \mathrm{~mL}$ of the mean orbital volume in males and $25.68 \mathrm{~mL}$ in females. 
We found that round shaped orbit was seen in 9 males and 16 females and square shaped orbits in 14 males and 6 females. The essential segments of the skeleton are the human skull and cranium which have received significant attention in forensic research especially in the analysis of ethno-racial relationship. The features within it may give further insight into the understanding of the craniofacial anthropometry. It is evident that a precise knowledge of anatomy of human body is essential to reach definitive diagnosis. Numerous diagnostic methods like computed tomography (CT scan), magnetic resonance imaging (MRI) is fruitful. These radiological tools no doubt provide essential information that helps in localizing lesions, pathologies as well as delineating vital structures but direct calculations on dry skulls is a more natural method in evaluating the orbital cavities.

Pretorious et al ${ }^{15}$ found that square shape of orbit was seen in $73.33 \%$ in males and round in $26.77 \%$ in females. Round shape was evident in $80 \%$ of subjects and square shape in $2 \%$ of subjects. Mekhala D observed that the orbit had two shapes round and square. $72 \%$ females exhibited round and $28 \%$ had square shape. $80 \%$ males had square shape and $20 \%$ had round shape of the skulls. According to Tripathi and Webb, ${ }^{16}$ three classes of orbits are recognized: megaseme (OI $>89$ ), mesoseme (OI between 89 and 83) and microseme (OI $\leq 83$ ). The orbital rim, as the margin of the orbital opening is a superficial structure that determines the orbitofacial appearance.

The shortcoming of the study was small sample size. Left and right orbits in males and females were not compared.

\section{CONCLUSIONS}

The mean orbital parameter measurements were more in males as compared to females. Exact and precise measurement of orbit is of paramount importance in avoiding injuries to the structures in order to obtain superior functional as well as esthetic results. Plastic surgery, oral and maxillofacial surgeries, and neurosurgeries demand more accurate measurements of orbits. It has a beneficial role in forensic science also. Race, ethnicity, age as well as gender can effectively be determined through measurements of orbital structures.

Data sharing statement provided by the authors is available with the full text of this article at jemds.com.

Financial or other competing interests: None.

Disclosure forms provided by the authors are available with the full text of this article at jemds.com.

\section{REFERENCES}

[1] Standring S. Gray's Anatomy: the anatomical basis of clinical practice. $38^{\text {th }}$ edn. London: Elsevier Ltd 2008:6556.

[2] Standring S. Gray's anatomy: the anatomical basis of clinical practice. $40^{\text {th }}$ edn. London: Elsevier Ltd 2008:6556.

[3] Xing S, Gibbon V, Clarke R, et al. Geometric morphometric analyses of orbit shape in Asian, African, and European human populations. Anthropological Science 2012:1-11.

[4] Sforza C, Grandi G, Catti F, et al. Age and sex-related changes in the soft tissues of the orbital region. Forensic Sci Int 2009;185(1-3):115.e1-8.

[5] Kaur J, Yadav S, Singh Z. Orbital dimensions: a direct measurement study using dry skulls. J Acad Indus Res 2012;1(6):293-5.

[6] Huanmanop T, Agthong S, Chentanez V. Surgical anatomy of fissures and foramina in the orbits of Thai adults. J Med Assoc Thai 2007;90(11):2383-91.

[7] Shimizu S, Tanriover N, Rhoton AL, et al. The MacCarty keyhole and inferior orbital fissure in orbitozygomatic craniotomy. Neurosurg 2005;57(1 Suppl):152-9.

[8] Rajangam S, Kulkarni RN, Quadrilos L, et al. Orbital dimensions. Indian Journal of Anatomy 2012;1(1):5-10.

[9] Sanjai S, Komon B, Aporn C, et al. Sex determination in Thai skulls by using craniometry: multiple logistic regression analysis. Siriraj Medical Journal 2007:59(5):216-21.

[10] Munguti J, Mandela P, Butt F. Referencing orbital measures for surgical and cosmetic procedures. Ant J Africa 2012;1(1):40-5.

[11] Weaver AA, Loftis KL, Tan JC, et al. CT scan based threedimensional measurement of orbit and eye anthropometry. Invest Ophthalmol Vis Sci 2010;51(10):4892-7.

[12] Patnaik VVG, Sanju B, Singla RK. Anatomy of the bony orbitsome applied aspect. J Anat Soc India 2001;50(1):5967.

[13] Gosavi SN, Jadhav SD, Zambre BR. A study of orbital morphometry in Indian dry skulls. Asian Journal of Biomedical and Pharmaceutical Sciences 2014;4(29):235.

[14] Fetouh FA, Mandour D. Morphometric analysis of the orbit in adult Egyptian skulls and its surgical relevance. Eur J Anat 2014;18(4):303-15.

[15] Pretorius E, Steyn M, Scholtz Y. Investigation into the usability of geometric morphometric analysis in assessment of sexual dimorphism. Am J Phys Anthropol 2006;129(1):64-70.

[16] Evans BT, Webb AAC. Post-traumatic orbital reconstruction: anatomical landmarks and the concept of the deep orbit. Br J Oral Maxillofac Surg 2007;45(3):1839. 